\title{
Incidence and Outcome of Ventilator Associated Pneumonia in ICU of a Tertiary Care Hospital in Nepal
}

\author{
Deebya Raj Mishra, ${ }^{1}$ Niharika Shah, ${ }^{2}$ Dibya Singh Shah ${ }^{3}$ \\ 'Department of Internal Medicine, B. P. Koirala Institute of Health Sciences, Dharan, Nepal, ${ }^{2}$ Department of Pathology, B. P. \\ Koirala Institute of Health Sciences, Dharan, Nepal, ${ }^{3}$ Department of Internal Medicine and Division of Nephrology and Renal \\ Transplant, Institute of Medicine, Tribhuvan University Teaching Hospital, Maharajgunj, Kathmandu, Nepal.
}

\section{ABSTRACT}

Introduction: Ventilator associated pneumonia is an important intensive care unit acquired infection in mechanically ventilated patients. Early and correct diagnosis of Ventilator associated pneumonia is difficult but is an urgent challenge for an optimal antibiotic treatment.

Methods: A prospective observational study was conducted in Intensive Care Unit of a tertiary care hospital in Nepal. Consecutive patients were considered during the study period, who met the criteria were included for the study. Clinical Pulmonary Infection Score was used to diagnose Ventilator associated pneumonia.

Results: Among 60 patients ventilated for more than 48 hours, 25 (41.6\%) developed ventilator associated pneumonia. The incidence was 25 VAPs per 100 ventilated patients or 26 VAPs per 1000 ventilator days during the period of study. Days on ventilator and duration in ICU were higher in the VAP group. There was a trend towards increasing mortality in the VAP group (P value $=0.06$ ) .

Conclusions: There exists a high rate of VAP in our Intensive Care Unit. Targeted strategies aimed at reducing Ventilator associated pneumonia should be implemented to improve patient outcome and reduce length of Intensive Care Unit stay and costs.

Keywords: clinical pulmonary infection score; incidence; ventilator associated pneumonia.

\section{INTRODUCTION}

Ventilator associated pneumonia (VAP) is an important form of hospital acquired pneumonia (HAP), specifically developing in a mechanically ventilated patient more than 48 hours after tracheal intubation. ${ }^{1}$ VAP is usually classified as either early onset, occurring within the first four days of Mechanical Ventilation or late onset, developing five or more days after initiation of Mechanical Ventilation. ${ }^{2}$ The diagnosis of VAP is often a problem due to the lack of sensitivity and specificity of clinical and radiographic signs of pneumonia in the patient population.
In Nepal, with its resource limitations, clinical judgment remains the most widely used method. However, refinements and uniformity in the clinical judgment can be brought about with the use of clinical criteria systematically. In this context, with the aim of simulating and quantifying the "clinical judgment", a score based on 6 variables, the Clinical Pulmonary

Correspondence: Dr. Deebya Raj Mishra, Department of Internal Medicine, B.P. Koirala Institute of Health Sciences, Dharan, Nepal. Email: deebyaraj@gmail.com, Phone: +977-9851134760. 
Infection Score (CPIS), was developed in 1991 by Pugin et al. $^{3}$ The usefulness of the CPIS was confirmed in studies by Flanagan et al, and Papazian et al. ${ }^{4,5}$

\section{METHODS}

On the background of limited research into Ventilator Associated Pneumonia, this study aims to find the incidence of VAP and compare the outcome characteristics including mortality among VAP and non VAP cases with systematic analysis of everyday clinical and investigative findings using the CPIS criteria.

The design of the study was Prospective Observational and conducted in an Intensive Care Unit (ICU) of a tertiary care center over a period of 1 year from August 2010 to July 2011. Written consent was taken from the patient or the patient party. As there was no estimated prevalence of VAP in Nepal, consecutive sampling was employed. Total 100 consecutive patients admitted and mechanically intubated were enrolled. Out of 100, 40 were excluded as they had a diagnosis of pneumonia at initial presentation, were suspected to have ARDS on admission, died within 48 hours or were transferred from ICU of other centers. Thus a total of 60 patients were considered for final analysis (Figure 1).

From each patient, the following data were collected at ICU admission: the demographic data, primary diagnosis, co-morbidities, date of admission in hospital and ICU. The study patients were monitored at every third day for the development of VAP using clinical and microbiological criteria until either discharge or death. The relevant data were recorded from medical records, bedside flow sheets, radiographic reports, and reports of microbiological studies of the patients. CPIS score of more than 6 was used to diagnose VAP. The organisms cultured and their antibiotic sensitivity pattern were noted in cases diagnosed as VAP.

Modified CPIS criteria was used for the diagnosis of VAP. ${ }^{6}$ CPIS at baseline was assessed on the basis of the first five variables, i.e. temperature, blood leukocyte count, tracheal secretions, oxygenation, and character of pulmonary infiltrate. CPIS at 72 hrs was calculated based on all seven variables and took into consideration the progression of the infiltrate and culture results of the tracheal aspirate. A score $>6$ at baseline or at 72 hrs was considered suggestive of pneumonia.

Tracheal aspirates were categorized as absent, nonpurulent or purulent as described by experienced senior sisters involved in daily care of the patients. Chest x-ray and progression of infiltrate were interpreted by the investigators and co-related with the reports given by radiologists. The culture reports were semi-quantitative.

Descriptive statistical analysis was done from the demographic data of patients. Results were expressed as mean $\pm \mathrm{SD}$. The Chi-Square test was used to compare discrete variables. Comparisons were unpaired and all tests of significance were two-tailed. Continuous variables were compared using Student's t-test for normally distributed variables. All statistical analyses were performed with computer based analysis software, SPSS version 17.0. $P$ values $<0.05$ were considered statistically significant.

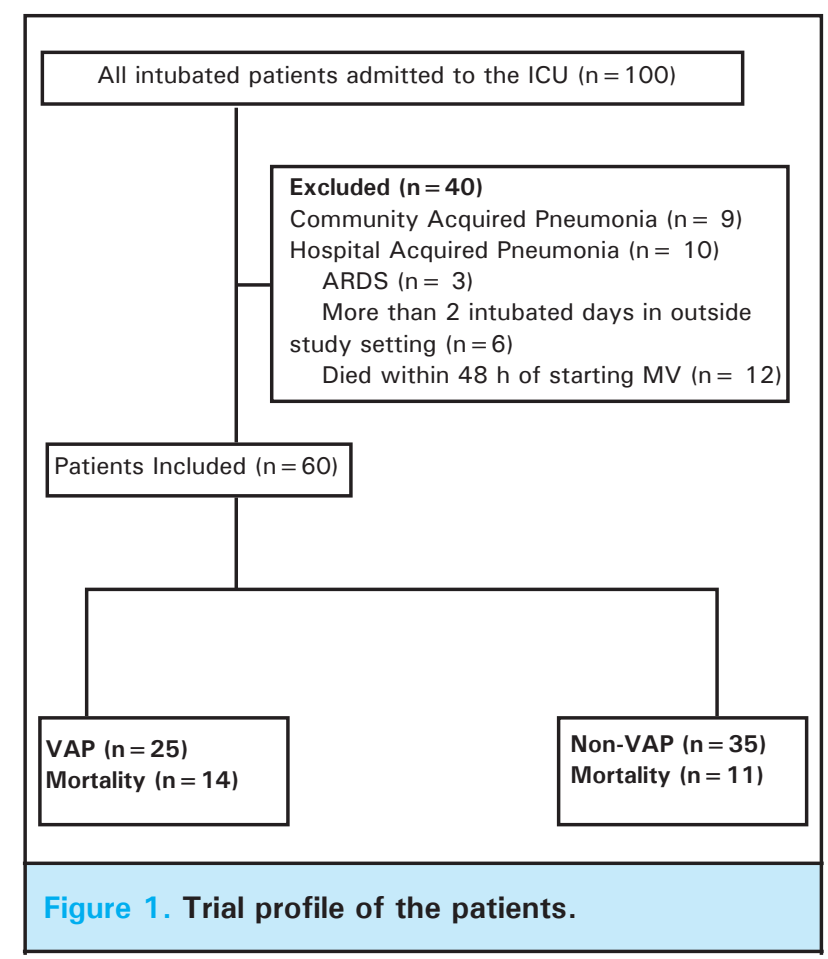

Table 1. Modified CPIS criteria.

$\begin{array}{llll}\begin{array}{l}\text { CPIS points } \\ \text { Temperature }(\mathrm{T})\end{array} & \mathbf{0} & \mathbf{1} & \mathbf{2} \\ & { }^{3} 36.5 \text { or } £ 38.4 & { }^{3} 38.5 \text { or } \leq 38.9 & { }^{3} 39 \text { or } £ 36 \\ & { }^{3} 97.7 \text { or } £ 101.2 & { }^{3} 101.3 \text { or }=102.1 & { }^{3} 102.2 \text { or } £ 96.8 \\ \text { WBC count (W) } & { }^{3} 4000 \text { or }=11,000 & <4000 \text { or }>11,000 & + \text { band forms }{ }^{3} 50 \% \\ \text { PaO2/FiO2 (O) } & >240 \text { or ARDS } & - & £ 240 \text { and no ARDS }\end{array}$




\begin{tabular}{|c|c|c|c|}
\hline $\begin{array}{l}\text { 4racheal secretions } \\
\text { (S) }\end{array}$ & Absent & Non-purulent & Purulent \\
\hline Chest X-ray (X) & No infiltrate & $\begin{array}{l}\text { Diffuse } \\
\text { (or patchy) infiltrate }\end{array}$ & Localized infiltrate \\
\hline $\begin{array}{l}\text { Progression of } \\
\text { Infiltrate (P.I.) }\end{array}$ & $\begin{array}{l}\text { No radiographic } \\
\text { progression }\end{array}$ & 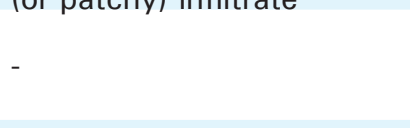 & $\begin{array}{l}\text { Radiographic progression } \\
\text { (after CHF and ARDS } \\
\text { excluded) }\end{array}$ \\
\hline $\begin{array}{l}\text { Culture of tracheal } \\
\text { aspirate (C) }\end{array}$ & $\begin{array}{l}\text { Pathogenic bacteria } \\
\text { cultured in rare or light } \\
\text { quantity or no growth }\end{array}$ & $\begin{array}{l}\text { Pathogenic bacteria } \\
\text { cultured in moderate or } \\
\text { heavy quantity }\end{array}$ & $\begin{array}{l}\text { Same pathogenic bacteria seen } \\
\text { on Gram stain, add } 1 \text { point }\end{array}$ \\
\hline
\end{tabular}

\section{RESULTS}

Of the 60 patients in the study cohort, by the use of CPIS criteria $>6$ for the diagnosis of VAP, 25(41.6\%) developed VAP. The overall incidence among the ventilated patients during the given duration was " 25 VAPs per 100 ventilated patients" or "26 VAPs per 1000 ventilator days" (25 of 976).

The most frequent causes of admission were abdominal surgery (including perforation peritonitis, gastrointestinal malignancy and abdominal trauma) in $9 / 60(16 \%)$, sepsis of unknown origin in 9/60 (16\%), neurosurgical trauma in $9 / 60(16 \%)$, cerebrovascular accidents in $7 / 60(12 \%)$ and CNS infection in $6 / 60$ $(10 \%)$ of the cases.

\begin{tabular}{|llll|}
\hline \multicolumn{3}{|l|}{ Table 2. Characteristics of the patients. } \\
\hline Parameter & VAP & Non-VAP & $\begin{array}{l}\text { P value } \\
\text { (2-tailed) }\end{array}$ \\
Age (Mean \pm SD) & 49.76 & $49.29 \pm$ & .926 \\
Gender & \pm 20.05 & 19.14 & \\
Male & & & \\
Female & 18 & 22 & \\
Primary Diagnosis & 7 & 13 & .581 \\
UGI Bleed & 0 & & \\
Fracture & 0 & 1 & \\
Pregnancy Related & 2 & 1 & \\
CNS Infection & 3 & 3 & \\
CVA & 2 & 5 & \\
Status Epilepticus & 1 & 0 & \\
MND/TM & 2 & 0 & \\
Sepsis & 6 & 3 & \\
COPD & 1 & 1 & \\
Neurosurgical Trauma & 2 & 7 & \\
Abdominal Surgery & 5 & 4 & \\
Acute Pancreatitis & 0 & 1 & \\
Poisoning & 0 & 2 & \\
Neurosurgical & 0 & 1 & \\
Malignancy & 1 & 5 & \\
Miscellaneous & 1 & 35 & \\
Total & 25 & & \\
\hline
\end{tabular}

Of the 60 patients, $20(33.3 \%)$ were female. The mean $\pm \mathrm{SD}$ age of patients receiving mechanical ventilation was $49.48 \pm 19.36$ years (range 6 to 87 years). The VAP and non-VAP groups were comparable for age, sex and the primary diagnosis (Table 2).

The onset of VAP was more likely to occur during the first 2 weeks of MV as $80 \%$ (20 out of 25) occurred during this period. Early-onset VAP developed in $44 \%$ (11 out of 25 ) of the cases, while the rest were lateonset VAP (Table 2).

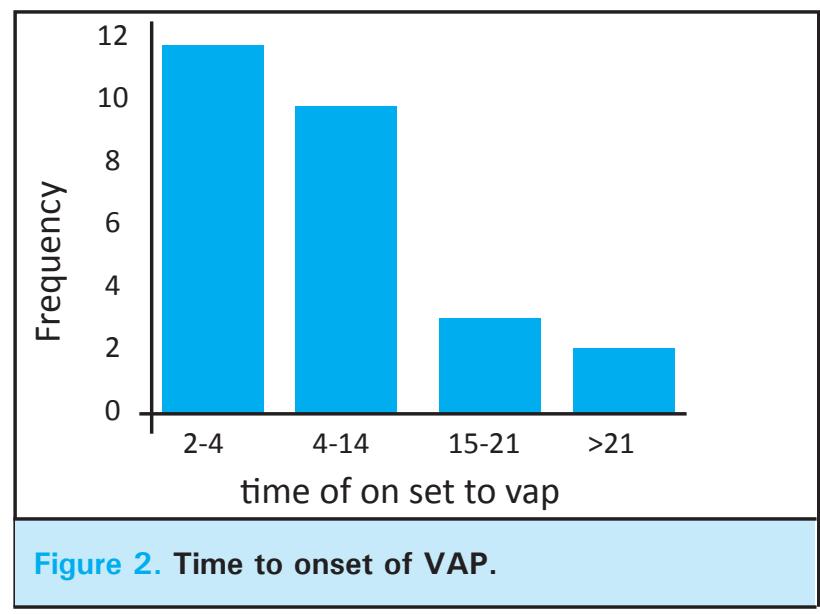

The VAP group had significantly longer duration in the ICU and also spent more days on the ventilator than the Non-VAP group (Table 3).

Table 3. Outcome characteristics.

\begin{tabular}{llll}
\hline $\begin{array}{l}\text { Parameters } \\
\text { Duration of }\end{array}$ & VAP & Non-VAP & P value \\
$\begin{array}{l}\text { ICU stay(days) } \\
\text { (mean } \pm \text { SD) }\end{array}$ & $19.60 \pm 15.72$ & $7.23 \pm 3.55$ & $<.0001$ \\
$\begin{array}{l}\text { Days on } \\
\text { Ventilator (days) } \\
\text { (mean } \pm \text { SD) }\end{array}$ & $18.16 \pm 16.075 .77 \pm 3.4$ & $<.0001$ \\
\hline
\end{tabular}

\begin{tabular}{|c|c|c|c|}
\hline Parameters & VAP & Non-VAP & $P$ value \\
\hline Mortality(n) & $14 / 25$ & $11 / 35$ & .06 \\
\hline
\end{tabular}


The mortality rate in the VAP group was $56 \%$ (14 out of 25$)$ and in the non-VAP group was $31.4 \%$ (11 out of 35$)$. Applying the Chi-Square test, $P$ value of .06 was obtained. Since this value lies between $0.1>P>$ 0.05 a trend is perceptible, which points to a distinction (Table 4).

\section{DISCUSSION}

VAP is a major threat to the recovery of patients receiving mechanical ventilation, and is one of the most important intensive care unit (ICU)-acquired infections in mechanically ventilated patients. In the European Prevalence of Infection in Intensive Care (EPIC) study, VAP was the most frequent infection, with about $45 \%$ of all infections in ICUs in Europe. ${ }^{7}$

No study to the best of our knowledge has been done in ICUs around Nepal regarding the different aspects of VAP. Our study gives a window into the scenario of our country.

The CPIS criteria proposed by Pugin et $\mathrm{al}^{3}{ }^{3}$ and its usefulness was confirmed in studies by Flanagan et al, and Papazian et al. ${ }^{4,5}$ The original score had 6 variables and used bronchoscopic method to obtain the culture specimen. Since bronchoscopic sampling in all patients was not possible in our setup, blinded endotracheal aspirate was analysed in our study. We also used Modified CPIS criteria consisting of 7 variables as given by Singh et al. ${ }^{6}$ The potential superiority of the modified CPIS over a "subjective" clinical prediction is to provide a single cutoff value using a reproducible method for calculation. The use of endotracheal aspirates have also been found comparable to those using invasive bronchoscopic methods in patients already receiving antibiotics, a clinical scenario very similar to ours where all the patients are already on antibiotics. ${ }^{8}$

The incidence of VAP in our study was "25 VAPs per 100 ventilated patients" or "26 VAPs per 1000 ventilator days" (25 of 976). Though there is large variation in incidence from center to center. The incidence of VAP in our study tallies with results reported previously. ${ }^{9,10}$ In the present study, $44 \%$ of cases were early-onset VAP, which is similar to other studies reporting early-onset VAP in almost half of all VAP episodes. ${ }^{11,12}$ It was observed that majority of the VAP $(80 \%)$ episodes occurred within the first two weeks of MV. The interaction of several risk factors during the initial days of MV put the patient at higher risk and also the exhaustion of most vulnerable patients during the first few weeks leads to the decline in the occurrence of VAP in later days. ${ }^{13}$
The duration of ICU stay and days on ventilator, both were significantly higher in the VAP group than in the non-VAP group. This trend is in agreement with other studies. ${ }^{12}$ These prolonged hospitalizations underscore the considerable financial burden imposed by the development of VAP.

There is wide variation in mortality rates among studies. Two independent factors make it difficult to assign responsibility unambiguously. The first is, once again, the difficulty in establishing a firm diagnosis, that is, to clearly identify patients with VAP; thus, the widely diverging VAP mortality rates reported might reflect not only differences in the populations studied but also differences in the diagnostic criteria used. Second, numerous studies have demonstrated that severe underlying illness predisposes patients in the ICU to the development of pneumonia, and their mortality rates are, consequently, high. ${ }^{7,14}$ Therefore, it is difficult to determine whether such patients would have survived if VAP had not occurred. Multivariate analyses conducted to evaluate the independent role played by VAP in inducing death failed to identify VAP as a variable independently associated with mortality in two studies. ${ }^{15,16}$ In contrast, the EPIC Study's stepwise logistic regression analyses demonstrated that ICUacquired pneumonia increased the risk of death with an Odds ratio of $1.91(95 \% \mathrm{Cl}, 1.6$ to 2.3$)$, independently of clinical sepsis and bloodstream infection. ${ }^{7}$ In our study, the $P$ value for mortality between the VAP and the non-VAP group was '0.06'. Since this value lies between $0.1>\mathrm{P}>0.05$ a trend is perceptible, which points to a distinction. Thus a trend towards higher mortality is seen in VAP cases. However we did not consider the severity of disease or organ dysfunction at admission, thus the role of these factors in contributing to mortality is not known in our study.

The study is limited by its small study population. As the best method of diagnosis of VAP is a subject of much debate, the use of CPIS criteria in our study in not exempt from such debates. The use of CPIS is on the premise that it has a high sensitivity for the diagnosis of VAP and due to the implications of VAP, a high sensitivity of the diagnostic modality is preferred. ${ }^{17}$ However, there are other studies where the usefulness of VAP has been questioned. ${ }^{18,19}$ Still, given the everyday variables and the ease of CPIS, we do believe it has a place in resource limited settings. We also did not look at the risk factors of VAP, thus without the use of logistic regression analysis, the attributable mortality due to VAP cannot be properly ascertained. Our study can only say that there was increased mortality in the VAP group but cannot say that the increased mortality is due to VAP. 


\section{CONCLUSIONS}

Our study shows a high level of VAP in the study setting along with its consequences of increased Ventilator and ICU days and a trend towards higher mortality. These worse outcomes in turn have massive social and financial implications. At the same time, the study also highlights the application of CPIS score in a low resource setting for diagnosis and monitoring of VAP, a feature which can be replicated in other ICUs around the country. Thus our study points to the need of bringing down the level of VAP with proven preventive measures in ICUs around the country.

\section{ACKNOWLEDGEMENTS}

We would like to thank Dr. Krishna K. Agrawaal, DM Resident, Nephrology at Nepal Medical College and Teaching Hospital in preparing the manuscript of this submission and final proof reading of this manuscript.

\section{Conflict of Interest: None.}

\section{REFERENCES}

1. Rajasekhar T, Anuradha K, Suhasini T, Lakshmi V. The role of quantitative cultures of non-bronchoscopic samples in ventilator associated pneumonia. Indian J Med Microbiol. 2006 Apr;24(2):107-13. [PubMed]

2. Langer M, Cigada M, Mandelli M, Mosconi P, Tognoni G. Early onset pneumonia: a multicenter study in intensive care units. Intensive Care Med. 1987;13(5):342-6. [PubMed]

3. Pugin J, Auckenthaler R, Mili N, Janssens JP, Lew PD, Suter PM. Diagnosis of ventilator-associated pneumonia by bacteriologic analysis of bronchoscopic and nonbronchoscopic bronchoalveolar lavage fluid. Am Rev Respir Dis. 1991 May;143(5 Pt 1):1121-9. [PubMed]

4. Flanagan PG, Findlay GP, Magee JT, Ionescu A, Barnes RA, Smithies M. The diagnosis of ventilator-associated pneumonia using non-bronchoscopic, non-directed lung lavages. Intensive Care Med. 2000 Jan;26(1):20-30. [PubMed]

5. Papazian L, Thomas P, Garbe L, Guignon I, Thirion X, Charrel $\mathrm{J}$, et al. Bronchoscopic or blind sampling techniques for the diagnosis of ventilator-associated pneumonia. Am J Respir Crit Care Med. 1995 Dec;152(6 Pt 1):1982-91. [PubMed]

6. Singh N, Rogers P, Atwood CW, Wagener MM, Yu VL. Short-course Empiric Antibiotic Therapy for Patients with Pulmonary Infiltrates in the Intensive Care Unit A Proposed Solution for Indiscriminate Antibiotic Prescription. Am J Respir Crit Care Med. 2000;162:505-11. [PubMed]

7. Vincent JL, Bihari DJ, Suter PM, Bruining HA, White J, Nicolas-Chanoin $\mathrm{MH}$, et al. The prevalence of nosocomial infection in intensive care units in Europe. Results of the European Prevalence of Infection in Intensive Care (EPIC) Study. EPIC International Advisory Committee. JAMA. 1995 Aug;274(8):639-44. [PubMed]

8. Wu CL, Yang DI, Wang NY, Kuo HT, Chen PZ. Quantitative Culture of Endotracheal Aspirates in the Diagnosis of Ventilator-Associated Pneumonia in Patients With Treatment Failure. Chest. 2002;122(2):662-8. [PubMed]

9. Jiménez $\mathrm{P}$, Torres A, Rodríguez-Roisin R, de la Bellacasa JP, Aznar R, Gatell JM, et al. Incidence and etiology of pneumonia acquired during mechanical ventilation. Crit Care Med. 1989 Sep;17(9):882-5. [ubMed]
10. George DL, Falk PS, Wunderink RG, Leeper K V, Meduri $\mathrm{GU}$, Steere EL, et al. Epidemiology of ventilator-acquired pneumonia based on protected bronchoscopic sampling. Am J Respir Crit Care Med. 1998 Dec;158(6):1839-47. [PubMed]

11. Chastre J, Fagon J. Ventilator-associated Pneumonia. Am J Respir Crit Care Med. 2002 Apr;165(7):867-903. [PubMed]

12. Cook DJ, Reeve BK, Guyatt GH, Heyland DK, Griffith LE, Buckingham L, et al. Stress ulcer prophylaxis in critically ill patients. Resolving discordant meta-analyses. JAMA. 1996 Jan;275(4):308-14. [PubMed]

13. Apostolopoulou E, Bakakos P, Katostaras T, Gregorakos $\mathrm{L}$. Incidence and risk factors for ventilator-associated pneumonia in 4 multidisciplinary intensive care units in Athens, Greece. Respir Care. 2003 Jul;48(7):681-8. [PubMed]

14. Chevret S, Hemmer M, Carlet J, Langer M. Incidence and risk factors of pneumonia acquired in intensive care units. Results from a multicenter prospective study on 996 patients. European Cooperative Group on Nosocomial Pneumonia. Intensive Care Med. 1993;19(5):256-64. [PubMed]

15. Kollef MH. Ventilator-associated pneumonia. A multivariate analysis. JAMA. 1993 Oct 27;270(16):1965-70. [PubMed]

16. Craven DE, Kunches LM, Kilinsky V, Lichtenberg DA, Make BJ, McCabe WR. Risk factors for pneumonia and fatality in patients receiving continuous mechanical ventilation. Am Rev Respir Dis. 1986 May;133(5):792-6. [PubMed]

17. 17. Baker AM, Bowton DL, Haponik EF. Decision Making in Nosocomial Pneumonia: An Analytic Approach to the Interpretation of Quantitative Bronchoscopic Cultures. Chest. 1995;107(1):85-95. [PubMed]

18. Croce MA, Swanson JM, Magnotti LJ, Claridge JA, Weinberg JA, Wood GC, et al. The futility of the clinical pulmonary infection score in trauma patients. J Trauma. 2006 Mar;60(3):523-7-8. [PubMed]

19. Schurink CAM, Van Nieuwenhoven CA, Jacobs JA, Rozenberg-Arska M, Joore HCA, Buskens E, et al. Clinical pulmonary infection score for ventilator-associated pneumonia: accuracy and inter-observer variability. Intensive Care Med. 2004 Feb;30(2):217-24. [PubMed] 